\title{
DOS-based exercises that demonstrate classic studies in human memory
}

\author{
LEONARD D. STERN \\ Eastern Washington University, Cheney, Washington
}

\begin{abstract}
Ten exercises are described that demonstrate some classic experiments in human memory and cognition. The studies, prepared in MEL Professional V1.0, have been incorporated in an undergraduate class taught by the author for a number of years. Survey data from students completing the course indicate that the exercises promote understanding of class material. Availability of the programs is described.
\end{abstract}

Instructors of undergraduate psychology courses often incorporate computer-controlled exercises into student laboratory experience (Hovancik, 1986) and report that student motivation and understanding of theoretical concepts consequently improve (Goernert, 1994). Software for this purpose is available in ready-to-run form (e.g., Experiments in Cognitive Psychology, Stanford University) or can be custom programmed using a tool-based (Goolkasian, 1997) package (e.g., SuperLab, Cedrus Corp., Phoenix, AZ); some tool-based packages include ready-to-run exercises (e.g., MacLaboratory, MacLaboratory, Inc., Devon, PA; MEL Professional, Psychology Software Tools, Inc., Pittsburgh, PA).

For a specialized course such as human memory and cognition the number of ready-to-run exercises is limited; thus, flexible tool-based packages must be relied on. As Eberhardt, Neverov, and Haneef (1997) have pointed out, however, there is a tradeoff between a tool-based program's flexibility and its ease of use. Programs such as Mindlab (Intellimation, Santa Barbara, CA) that can be easily used have limitations (e.g., restricted to collecting single key or mouse-click responses; Goernert, 1994). On the other hand, a flexible program such as MEL may require incorporating computer code written in a language resembling PASCAL that puts it beyond the abilities of the average user (Pallier, DuPoux, \& Jeannin, 1997). As a result, many instructors must rely on ready-to-run exercises for their student laboratory experience.

The intent of this report is to announce the availability of a set of ready-to-run exercises that illustrate some classic experiments often discussed in undergraduate memory and cognition courses. The exercises were prepared using MEL Professional V1.0. Several criteria underlay their preparation. Each was intended to be faithful to the original procedures, present a student with all representative experimental conditions, and involve a minimum of tedium. Some of these criteria conflict. Using abbreviated

This work was supported in part by Instrumentation and Laboratory Improvement Grant USE-9251161 from the National Science Foundation. Correspondence should be addressed to L. D. Stern, Department of Psychology, MS 94, Eastern Washington University, Cheney, WA 99004 (e-mail: 1stern@ewu.edu). sets of stimuli to reduce monotony required departing from original procedures, as did requiring participants to experience all experimental conditions when the original studies manipulated independent variables between subjects.

\section{DESCRIPTION OF THE EXERCISES}

Each exercise will be briefly described by summarizing the original research, indicating how the simulation implements the original procedure, and presenting some representative data produced by students in a cognitive psychology class that has most recently been assigned the exercise. References to more current views on each research topic are also provided.

\section{Retrieval From Semantic Memory}

The exercise illustrates the approach used to test a model of semantic memory proposed by Collins and Quillian (1969) that posited a hierarchical arrangement of concept nodes with property information associated to concept nodes at the most abstract level possible. By making some assumptions about the time course of retrieval (e.g., it takes time to move one node up the hierarchy), Collins and Quillian (1969) were able to test their model using true and false sentences that subjects were instructed to verify. Sentences expressed subset-superset (e.g., an oak is a tree) or property (e.g., an oak has branches) relations. A fundamental prediction was that sentence verification times for true sentences would increase linearly with the number of nodes separating concepts in the theoretical network (e.g., time to verify "a canary is a canary" < "a canary is a bird" < "a canary is an animal").

For student participants who recently completed this exercise $(N=25)$, mean response latencies to answer true sentences expressing subset-superset relations that required spanning zero, one, or two levels in the theoretical network were $1,216,1,399$, and $1,732 \mathrm{msec}$, respectively. For true sentences in corresponding conditions expressing property relations, mean response latencies were 1,589, 1,727 , and 1,792 msec. Analyses of variance (ANOVAs) revealed a significant linear trend of response latencies across number of levels in the hierarchy for subset-super- 
set $[F(1,24)=33.92, p<.001]$ and property $[F(1,24)=$ $5.45, p<.05]$ relations. The linear trend did not differ significantly over the variable type of relation.

Models of semantic memory that address shortcomings of the Collins and Quillian (1969) approach have been proposed by Rips, Shoben, and Smith (1973) and Collins and Loftus (1975). More recent approaches to knowledge representation are offered by Anderson (1983), Rumelhart, McClelland, and the PDP Research Group (1986), and Masson (1995).

\section{Analog Representation of Visual Information}

To test whether mental images were analog rather than propositional representations of percepts, Kosslyn (1975) induced subjects to generate mental images of various animals that were relatively large or small by having them image the animal in the proximity of a fly or an elephant, respectively. Kosslyn (1975) demonstrated that features of small images were more difficult to resolve than those of large images: Subjects who were given the name of a property to verify as appropriate or not to the target (e.g., the property legs for the target goose) took an average of $211 \mathrm{msec}$ longer when the target was small as opposed to when it was large.

In the simulation, the name of the context animal ( $f l y$, elephant) is presented, followed by the name of the target animal. After $6 \mathrm{sec}$, the name of a property is shown. To more closely mimic Kosslyn's (1975) procedure in which stimuli were presented by a tape recorder, students in my cognition class do the simulation twice: once reading the names of the stimuli from the screen, and once having another student reading aloud all the stimuli. Analysis of latency data generated by a class $(N=20)$ showed that mean response time in the large $(M=1,729 \mathrm{msec})$ and small $(M=1,833 \mathrm{msec})$ conditions differed significantly when the stimulus presentation was auditory $[F(1,19)=4.40$, $p<.05$ ] but not when it was visual (both $M \mathrm{~s}=1,370 \mathrm{msec}$ ).

Further work on the nature of mental imagery is summarized in Kosslyn (1994). Additional insights into the relation of mental imagery to visual perception have come from investigations of imagery's underlying neural mechanisms (e.g., Farah, 1988; Ishai \& Sagi, 1995).

\section{Role of the Short-Term Store in the Recency Effect}

Glanzer, Gianutsos, and Dubin (1969) were concerned with the mechanism by which information is removed from the short-term store. A key finding in their study was that having subjects read 6 distractor words before free recalling a list of 12 words eliminated the recency effect. This was interpreted as evidence that information in the short-term store can be removed by new information entering the system.

In the simulation, participants study and free recall ten 12-word lists, half of which are followed by 6 distractor words. Analysis of the serial position curves produced by a cognitive psychology class $(N=36)$ for the no-distractor and distractor conditions of this exercise revealed that the mean number of words recalled in the last three serial positions combined differed significantly in the distractor $(M=6.9)$ and no-distractor $(M=9.5)$ conditions $[F(1,35)=$ $22.14, p<.001]$ but not in the first three serial positions combined ( $M=9.3$ for distractor condition; $M=9.4$ for no-distractor condition; $F<1$ ).

More recent work on mechanisms underlying the recency effect (e.g., Bjork \& Whitten, 1974; Greene, 1986) has called into question the two-store model (e.g., Atkinson \& Shiffrin, 1968) interpretation and has contributed to the development of other theoretical accounts (e.g., Baddeley, 1992; Nairne, 1990).

\section{Buildup and Release From Proactive Interference}

That forgetting in a short-term memory task can be due to proactive interference and that proactive interference is a function of class similarity between to-be-recalled and previously tested information was demonstrated by Reutener (1972), Wickens (1972), and others (e.g., Loess, 1964). In the study by Reutener, subjects read four sets of three names of different articles of furniture and then recalled the names in each set after about $20 \mathrm{sec}$ of distractor activity. Memory performance was found to decrease over sets. However, when the fourth set of stimuli was three numbers, memory performance was significantly better than that on the previous set.

In the simulation of the study, four blocks of trials are presented: two show four sets of three words from the same conceptual category (no-shift condition) and two show three consecutive sets of three words from the same conceptual category followed by a set of three numbers on the fourth trial (shift condition). Mean proportions correct recall for Trials $1-4$ in the no-shift condition were $.86, .75$, .71 , and .75 , respectively, for students $(N=33)$ recently completing the simulation; their corresponding data for the shift condition were $.86, .81, .78$, and .90 . ANOVAs revealed that for Trials $1-3$ there was a linear effect of trial for the no-shift and shift conditions combined $[F(1,32)=$ $14.07, p<.001]$ that did not interact significantly with condition $(F<2)$; and recall on the fourth trial of the two conditions differed significantly $[F(1,32)=11.11, p<.01]$.

The theoretical ideas underlying the phenomenon of buildup and release from proactive interference continue to be useful, and the paradigm still plays a role in assessing the cognitive abilities of memory-impaired populations (see, e.g., Smith, Leonard, Crane, \& Milner, 1995).

\section{Acoustic Coding in Short-Term Memory}

The detrimental effect of acoustic similarity on shortterm ordered recall was demonstrated in Baddeley's (1966) study. Some subjects were presented with sets of five acoustically similar (e.g., man, mad, mat) words and sets of five acoustically different words; others received sets of 
semantically similar and semantically different words. Acoustic similarity was found to be significantly more detrimental to ordered recall than was semantic similarity.

In the simulation of the study, lists of five words are presented at a rate of approximately one word per sec for immediate ordered recall. One block of trials consists of four acoustically similar and four acoustically different lists, in random order; another block consists of four semantically similar and four semantically different lists, also in random order. Representative data from class participants $(N=28)$ revealed that proportion correct ordered recall for acoustically similar lists $(M=.56)$ differed significantly from that for acoustically different lists $(M=$ .89) $[F(1,27)=141.84, p<.001]$; however, performance on the semantically similar $(M=.79)$ and semantically different $(M=.83)$ lists did not differ significantly $(F<2)$.

The differential detrimental effect of acoustic over semantic similarity on ordered recall was used to support the idea that a store other than the long-term store mediated performance on the task. Considerable additional work has been done to characterize the memory system responsible (e.g., Baddeley, 1986; Longoni, Richardson, \& Aiello, 1993; Martín-Loeches, Schweinberger, \& Sommer, 1997).

\section{Interacting Imagery in Paired-Associate Learning}

To investigate the relative effectiveness of different strategies for learning paired associates, Bower and Winzenz (1970) instructed subjects to learn lists of 30 pairs of concrete nouns using one of four tasks: rehearse each word pair; read a sentence that incorporated the pair of words; generate a sentence that sensibly related the words; or generate a mental image of the referents of the two words interacting. Memory performance as tested by cued recall and recognition was best in the interacting imagery condition and worst for the rehearsal condition.

The simulation of the study presents three lists of 15 pairs of concrete nouns for paired-associate learning under instructions that differ for each list: rehearse the words in each pair, generate a meaningful sentence that relates the words in each pair, or form an interacting image based on the words in each pair. Memory is tested immediately after list presentation with a cued recall procedure.

Statistical analysis of data from class participants $(N=$ 28) showed that mean proportion correct performance for the rehearsal, sentence generation, and interacting imagery conditions $(.37, .79$, and .90 , respectively) differed significantly $[F(1,27)=86.66, p<.001]$, as did all pairwise comparisons of means $(t \mathrm{~s}>3.02, p<.01)$.

A recent review of mnemonics and their effectiveness is given by Belezza (1996).

\section{Keyword Method}

The effectiveness of the keyword method in learning foreign vocabulary was demonstrated by Atkinson and Raugh (1975). To use the method, a person pronounces a foreign word and finds an English word (the keyword) that sounds like all or part of the foreign word, then forms a mental image of the referents of the keyword and English translation interacting. Their data showed that students who used the method provided the correct translations of Russian words $72 \%$ of the time, whereas the students in the control condition provided the correct translations $46 \%$ of the time.

In the simulation, a list of 10 foreign words-either Russian or Spanish, depending on which is selected as being the less familiar language-is shown, together with English translations. Two lists are presented for study in the control condition. The keyword method is then explained, and participants are told to apply it to learning the next two lists. Each list is presented and tested twice. For the test, participants are cued with the foreign word and requested to provide the English translation.

Proportion correct cued recall for class data $(N=51)$ was .61 and .89 on Trials 1 and 2, respectively, in the control condition and .67 and .93 for Trials 1 and 2, respectively, in the keyword condition. An ANOVA revealed that performance in the keyword condition was significantly different from that in the control condition $[F(1,50)=$ $4.03, p<.05]$.

Recent investigations of the effectiveness of the keyword method are found in Gruneberg and Pascoe (1996) and Wang, Thomas, Inzana, \& Primicerio (1993).

\section{Levels-of-Processing Effect}

In a series of experiments, Craik and Tulving (1975) provided data to support the idea that memory retention was determined by the depth at which a stimulus was processed (Craik \& Lockhart, 1972). One study presented words for processing using a typecase (e.g., is the word in uppercase letters?) rhyme (e.g., does the word rhyme with gate?) or sentence judgment (e.g., does the word fit into the sentence The boy threw a__? task and tested memory with a yes/no recognition procedure. Words processed using the sentence judgment task were most often recognized and words processed using the typecase task were least often recognized. In addition, words for which the correct answer on the processing task was "yes" were more often recognized than those for which the correct answer was "no."

In the simulation of the study, 48 words are presented for processing, using a typecase, rhyme, or sentence judgment task, followed by a yes/no recognition test. Hit rates from a class $(N=30)$ for words given "yes" responses that were processed using the typecase, rhyme, and sentence judgment task were $.37, .77$, and .87 , respectively, and hit rates for words given "no" responses for these three tasks were $.31, .49$, and .76 , respectively. The proportions differed significantly as a function of processing tasks for "yes" $[F(2,58)=77.59, p<.001]$ and "no" $[F(2,58)=$ $54.07, p<.001]$ responses. In addition, the hit rates for "yes" and "no" responses differed significantly $[F(1,29)=$ $22.97, p<.001]$. 
Although the levels-of-processing view has been modified in some ways (e.g., Anderson \& Reder, 1979), it continues to be applied usefully in studies of human cognition (e.g., Challis, Velichovsky, \& Craik, 1996).

\section{Implicit Memory}

To demonstrate that elaboration and integration are distinct memory processes that can be dissociated in normal subjects, Graf, Mandler, and Haden (1982) presented a list of words to be processed either elaboratively (rated for liking) or shallowly (judged as to whether the word shared any vowels with the preceding word in the list) and tested memory with a free recall or word-stem completion procedure (i.e., form a word that begins with the three letters provided). The study manipulation was found to affect only performance on the recall test (which is assumed to be sensitive to elaboration), not the word-stem completion test (which is assumed to depend mainly on integration).

In the simulation, each participant sees two lists of words and processes one using liking judgments and the other with vowel judgments (randomly ordered). A word-stem completion test is followed by a free recall test. Mean number of words free recalled by a class $(N=28)$ was 4.0 in the elaboration condition and 1.6 in the vowel condition, values that differed significantly $[F(1,27)=44.77$, $p<.001]$. In the word-stem completion test, the difference between mean priming scores in the elaboration and vowel conditions (.25 and .17, respectively) approached significance $[F(1,27)=4.20, p<.06]$.

In accord with the results obtained in the simulation, recent work has called into question the finding that level of processing does not affect performance on certain implicit memory tasks (e.g., Brown \& Mitchell, 1994; Challis \& Brodbeck, 1992).

\section{Implicit Learning of àn Artificial Grammar}

In Reber's (1967) artificial grammar learning paradigm, strings of letters generated by a finite-state grammar are presented for learning. A test includes new "grammatical" strings generated from the same rules as those used in the learning phase, and ungrammatical strings. Implicit learning of the artificial grammar is demonstrated by above chance identification performance (over $70 \%$ correct, Experiment 2 ).

In the simulation, 20 strings of three to six letters are shown in five sets of 4 , each set followed by a free recall test (this learning procedure is modeled after Reber \& Allen, 1978). Following the learning phase is a test on 20 new grammatical and 20 ungrammatical strings. Mean correct performance by a class $(N=29)$ was $60 \%$, a value that differed significantly from chance $[t(28)=6.32, p<$ .0011 .

Recent work on implicit learning of artificial grammar has focused on the extent to which the learning is abstract and implicit (Dienes \& Berry, 1997; Dulany, Carlson, \& Dewey, 1984; Neal \& Hesketh, 1997; Servan-Schreiber \& Anderson, 1990).

\section{CLASSROOM EVALUATION OF THE EXERCISES}

These exercises have been incorporated in an undergraduate memory and cognition class taught at Eastern Washington University during the past several years. To assess the extent to which the exercises have promoted understanding of class material, a survey administered to four classes requested that students evaluate this on a scale of 1 to 5, where 1 signaled a great deal and 5 signaled not at all. Of the 105 students completing the survey, the percentages selecting the response categories 1 to 5 were 46, $36,11,7$, and 0 , respectively. Another issue addressed on the survey was the effectiveness of the instructions guiding each exercise. On a scale of 1 to 5 , where 1 signaled very good and 5 signaled poor, the percentages of students giving the ratings 1 to 5 were $56,30,11,1$, and 2 , respectively. To evaluate the time needed to complete each exercise on the computer, students were asked to provide an estimate in minutes. The mean estimate was $16.4 \mathrm{~min}$ with a standard deviation of $5.4 \mathrm{~min}$.

Most of the students completing these surveys between 1993 and 1996 indicated that they did not have a lot of computer experience: For the categories $1=$ little or no experience, 2 = some experience (e.g., introductory computer course or word processing experience), and $3=a$ lot of experience (e.g., computer programming), the percentages of students endorsing the options 1 to 3 were 22, 62, and 16, respectively. Because of this limitation, and because MEL runs in DOS, which is becoming less frequently used, I have found it most efficient to control presentation of the exercises with batch programs. Turning on a laboratory computer presents a menu of programs and running a program requires only typing in a number corresponding to a menu item.

Availability. Licensed MEL users can receive a copy of the programs on a 3.5-in. disk. Those who do not have MEL but have a system running MS-DOS 3.0 or above can send for a 3.5-in. disk containing the programs that will run in demonstration mode (which does not permit modifying the programs or having results written to a disk file). Please send $\$ 5$ to Leonard Stern, Department of Psychology, MS 94, Eastern Washington University, Cheney, WA 99004. Specify whether or not you are a licensed MEL user.

\section{REFERENCES}

Anderson, J. R. (1983). The architecture of cognition. Cambridge, MA: Harvard University Press.

ANDERSON, J. R., \& REDER, L. (1979). An elaborative processing explanation of depth of processing. In L. S. Cermak \& F. I. M. Craik (Eds.), Levels of processing in human memory (pp. 385-403). Hillsdale, NJ: Erlbaum.

AtKInSON, R. C., \& RaUgh, M. R. (1975). An application of the mnemonic keyword method to the acquisition of a Russian vocabulary. Journal of Experimental Psychology: Human Learning \& Memory, 1, 126-133.

Atkinson, R. C., \& Shiffrin, R. M. (1968). Human memory: A pro- 
posed system and its control processes. In K. W. Spence \& J. T. Spence (Eds.), The psychology of learning and motivation (Vol. 2, pp. 89105). New York: Academic Press.

BADDELEY, A. D. (1966). Short-term memory for word sequences as a function of acoustic, semantic, and formal similarity. Quarterly Journal of Experimental Psychology, 18, 362-365.

BADDELEY, A. D. (1986). How does acoustic similarity influence shortterm memory? Quarterly Journal of Experimental Psychology, 20, 249-264.

BADDEleY, A. D. (1992). Working memory. Science, 255, 556-559.

BELEZZA, F. (1996). Mnemonic methods to enhance storage and retrieval. In E. L. Bjork \& R. A. Bjork (Eds.), Handbook of perception and cognition (pp. 354-380). San Diego: Academic Press.

BJoRK, R. A., \& WhITTEN, W. B. (1974). Recency-sensitive retrieval processes in long-term free recall. Cognitive Psychology, 6, 173-189.

BOWER, G. H., \& WINZENZ, D. (1970). Comparison of associative learning strategies. Psychonomic Science, 20, 119-120.

Brown, A. S., \& MitCHELL, D. B. (1994). A reevaluation of semantic versus nonsemantic processing in implicit memory. Memory \& $\mathrm{Cog}$ nition, 22, 533-541.

Challis, B. H., \& Brodbeck, D. R. (1992). Level of processing affects priming in word fragment completion. Journal of Experimental Psychology: Learning, Memory, \& Cognition, 18, 595-607.

Challis, B. H.,Velichovsky, B. M., \& Craik, F. I. M. (1996). Levelsof-processing effects on a variety of memory tasks: New findings and theoretical implications. Consciousness \& Cognition, 5, 142-164.

Collins, A. M., \& Loftus, E. F. (1975). A spreading activation theory of semantic processing. Psychological Review, 82, 407-428.

Collins, A. M., \& Quillian, M. R. (1969). Retrieval time from semantic memory. Journal of Verbal Learning \& Verbal Behavior, 8 , 240-247.

CRAIK, F. I. M., \& LockHART, R. S. (1972). Levels of processing: A framework for memory research. Journal of Verbal Learning \& Verbal Behavior, 11, 671-684.

Cralk, F. I. M., \& Tulving, E. (1975). Depth of processing and the retention of words in episodic memory. Journal of Experimental Psychology: General, 104, 268-294.

DiENES, Z., \& BERRY, D. (1997). Implicit learning: Below the subjective threshold. Psychonomic Bulletin \& Review, 4, 3-23.

Dulany, D. E., Carlson, R. A., \& Dewey, G. I. (1984). A case of syntactical learning and judgment: How conscious and how abstract? Journal of Experimental Psychology: General, 113, 541-555.

Eberhardt, S. P., Neverov, M., \& Haneef, O. (1997). RunScript: An extendible object-oriented program for computer-controlled psychology experiments. Behavior Research Methods, Instruments, \& Computers, 29, 313-321.

FARAH, M. J. (1988). Is visual imagery really visual? Overlooked evidence from neuropsychology. Psychological Review, 95, 307-317.

Glanzer, M., Gianutsos, R., \& Dubin, S. (1969). The removal of items from short-term storage. Journal of Verbal Learning \& Verbal Behavior, 8, 435-447.

GoERNERT, P. N. (1994). MindLab: A software tool for integrating interactive microcomputer exercises into the classroom. Teaching of Psychology, 21, 184-186.

Gool-Kasian, P. (1997). Microcomputers in the social sciences: A new course. Teaching of Psychology, 24, 204-206.

Graf, P., Mandler, G., \& Haden, P. E. (1982). Simulating amnesic symptoms in normal subjects. Science, 218, 1243-1244.

GREENE, R. L. (1986). Sources of recency effects in free recall. Psychological Bulletin, 99, 221-228.
Gruneberg, M. M., \& Pascoe, K. (1996). The effectiveness of the keyword method for receptive and productive foreign vocabulary learning in the elderly. Contemporary Educational Psychology, 21, 102-109.

HovaNCIK, J. R. (1986). Using microcomputers in the undergraduate laboratory. Teaching of Psychology, 13, 94-95.

IsHAI, A., \& SAGI, D. (1995). Common mechanisms of visual imagery and perception. Science, 268, 1772-1777.

KossLYN, S. M. (1975). Information representation in visual images. Cognitive Psychology, 7, 341-370.

KossLYN, S. M. (1994). Image and brain: The resolution of the imagery debate. Cambridge, MA: MIT Press.

LoESs, H. (1964). Proactive inhibition in short-term memory. Journal of Verbal Learning \& Verbal Behavior, 3, 362-368.

Longoni, A. M., Richardson, J. T. E., \& Aiello, A. (1993). Articulatory rehearsal and phonological storage in working memory. Memory \& Cognition, 21, 11-22.

Martín-Loeches, M., SCHWEINBerger, S. R., \& Sommer, W. (1997). The phonological loop model of working memory: An ERP study of irrelevant speech and phonological similarity effects. Memory \& Cognition, 25, 471-483.

Masson, M. E. J. (1995). A distributed memory model of semantic priming. Journal of Experimental Psychology: Learning, Memory, \& Cognition, 21, 3-23.

NaIRNE, J. S. (1990). A feature model of immediate memory. Memory \& Cognition, 18, 251-269.

Neal, A., \& Hesketh. B. (1997). Episodic knowledge and implicit learning. Psychonomic Bulletin \& Review, 4, 24-37.

Pallier, C., DuPoux, E., \& JeAnnin, X. (1997). EXPE: An expandable programming language for on-line psychological experiments. $B e$ havior Research Methods, Instruments, \& Computers, 29, 322-327.

REBER, A. S. (1967). Implicit learning of artificial grammars. Journal of Verbal Learning \& Verbal Behavior, 6, 855-863.

Reber, A. S., \& AlLEN, R. (1978). Analogic and abstraction strategies in synthetic grammar learning: A functionalist interpretation. Cognition, 6, 189-221.

REUTENER, D. B. (1972). Background, symbolic, and class shift in shortterm verbal memory. Journal of Experimental Psychology, 93, 90-94.

Rips, L. J., Shoben, E. J., \& SMith, E. E. (1973). Semantic distance and the verification of semantic relations. Journal of Verbal Learning \& Verbal Behavior, 14, 1-20.

Rumelhart, D. E., MCClelland, J. L., \& The PDP Research Group (EDs.) (1986). Parallel distributed processing: Explorations in the microstructure of cognition. Vol. 1: Foundations. Cambridge, MA: MIT Press.

Servan-SChreiber, D., \& ANDERSON, J. R. (1990). Learning artificial grammars with competitive chunking. Journal of Experimental Psychology: Learning, Memory, \& Cognition, 16, 592-608.

Smith, M. L., Leonard, G., Crane, J., \& Milner, B. (1995). The effects of frontal- or temporal-lobe lesions on susceptibility to interference in spatial memory. Neuropsychologia, 33, 275-285.

Wang, A. Y., Thomas, M. H., InZana, C. M., \& Primicerio, L. J. (1993). Long-term retention under conditions of intentional learning and the keyword mnemonic. Bulletin of the Psychonomic Society, 31, 545-547.

WICKENS, D. D. (1972). Characteristics of word encoding. In A. W. Melton \& E. Martin (Eds.), Coding processes in human memory (pp. 191-215). Washington, DC: Winston.

(Manuscript received October 31, 1997; revision accepted for publication August 5, 1998.) 